\title{
Funding Growth and Service Match: Doing More of the Same, or Doing Things Better?
}

\author{
Heather Stuart, Terry Krupa, and Michelle Koller \\ Queen's University
}

\begin{abstract}
We evaluated service access and match in Southeastern Ontario following community mental health funding increases using repeated samples drawn before and after the enhancements. Access to care increased by an estimated 12\% (350 clients) between 2001 and 2006, but only about a third of clients were appropriately matched to their needed level of care. Service match increased slightly after the funding increases, but changes were non-statistically significant. Almost half of the clients remained underserviced and $20 \%$ were overserviced, suggesting that a more targeted and systematic approach to care planning is necessary to shift systemwide resources to client groups who are in the greatest need.
\end{abstract}

Between 2000 and 2006, resources directed to the Southeastern Ontario community mental health system (serving some 500,000 people) more than doubled, resulting in a cumulative increase of almost $\$ 19$ million. Similar funding enhancements occurred in every region of the province. In preparation for hospital downsizing, new funding was targeted to expand community programs such as intensive case management, assertive community treatment, crisis intervention, early intervention, supported housing, and court support. New funding was intended to improve access to appropriate community-based treatments and reduce hospital utilization (Systems Enhancement Evaluation Initiative, 2009).

We evaluated access to care and service match in the Southeastern Ontario community mental health sector to determine if there had been improvements following the funding enhancements. Access to care refers to the number of unique clients served in the community and addresses the ability of the system to

Heather Stuart, Centre for Health Services and Policy Research, Queen's University, Kingston, Ontario; Terry Krupa, School of Rehabilitation Therapy, Queen's University, Kingston, Ontario; Michelle Koller, PhD student, Department of Community Health and Epidemiology, Queen's University, Kingston, Ontario.

Funding for this study was provided by the Ontario Mental Health Foundation. The authors wish to thank the community mental health providers who participated in data collection, and the key informants who assisted us with interpretation and knowledge translation.

Correspondence concerning this article should be addressed to Heather Stuart, Centre for Health Services and Policy Research, Abramsky Hall (3 ${ }^{\text {rd }}$ Floor), Queen's University, Kingston, ON K7L 3N6. Email: heather.stuart@queensu.ca 
meet previously unmet need (doing more of the same). Service match reflects the ability of the system to deliver appropriate care to existing clients (doing things better). Service match was understood in the context of a "level of care" planning model that links a predefined intensity of services to clients' psychosocial and rehabilitation needs (Durbin, Cochrane, Goering, \& Macfarlane, 2001; McGee \& Mee-Lee, 1997; Uehara, Srebnik, \& Smukler, 2003).

\section{BACKGROUND}

Program planners face significant challenges in reorienting mental health systems to better meet population mental health needs. Epidemiologic studies have shown that mental disorders occur in $20 \%$ of the population each year, but that fewer than half will seek treatment, reflecting high levels of unmet need (Vasiliadis, Lesage, Adair, \& Boyer, 2005). Barriers to accessing care include perceptions of need, as well as a range of social and psychological variables such as ethnicity, social support, and attitudes toward mental disorders or help seeking (Sareen, Cox, Afifi, Clara, \& Yu, 2005). Using data from the National Comorbidity Survey in the United States, Kessler and colleagues (2001) showed that fewer than $40 \%$ of the $6.2 \%$ of respondents with a serious mental illness received adequate treatment. Over half did not receive treatment because they did not perceive a need. Other major reasons for not seeking care were the desire to solve the problem on their own and the belief that the problem would get better by itself (Kessler et al., 2001).

Quality mental health care depends on the system's ability to better match the level of care provided to clients' psychosocial needs. Mental health service researchers have also demonstrated that people receiving treatment, such as community mental health clients, have high levels of unmet need (Ruggeri et al., 2004). Some of these unmet needs can be related to system characteristics such as whether integrated, continuous care is provided. The highest levels of unmet need have been documented for social and recreational interventions (Wiersma et al., 2008). In addition to unmet need, however, there is also evidence that a significant portion of clients are overserviced by community agencies. These clients receive a range or intensity of services that exceeds their psychosocial needs (Alonso et al., 2007; Durbin et al., 2001).

In preparation for hospital downsizing in Ontario, Durbin and colleagues (2001) developed and validated a level-of-care planning model to identify the additional community resources that would be required to support planned restructuring. The model became an important tool for reorganizing psychiatric services across the province, and elsewhere. The model compares the level of care recommended for each client to the level of care actually received, to determine service match. When applied to inpatients in a provincial psychiatric hospital, only $10 \%$ were recommended to remain in hospital. Thirty percent were recommended for a supervised residential placement, and 60\% were recommended for community care. When applied to community-based clients, the model identified important treatment gaps. In Southeastern Ontario, only $30 \%$ of the community clients surveyed received an intensity of service that matched their psychosocial needs (Stuart, 2002). In the Ottawa-Champlain District, 38\% of clients received a level of care that matched their needs (Durbin, Koegl, et al., 2002), and in the Toronto-Peel District, 35\% were appropriately matched (Durbin, Baranek, et al., 2002). These results were used by the Ministry of Health and Long-Term Care to support significant funding enhancements to the community mental health system in Ontario in preparation for hospital downsizing. 
Hansen and colleagues also used this model to assess service match in the Fraser Health Region of British Columbia (Hansen, Houde, McDowell, \& Dixon, 2007). They found that fewer than half of case management clients (44\%) received the appropriate level of care. Of these, $22 \%$ were recommended to a lower level of care (so had been overserviced), and $36 \%$ were recommended to a higher level of care (so had been underserviced). With respect to intensive case management, $42 \%$ of clients were recommended to a lower level of care and $8 \%$ were recommended to a higher level of care. Finally, $58 \%$ of residential care clients were recommended for a lower level of care ( $43 \%$ of these to intensive case management), and $13 \%$ were recommended for hospital care.

These studies demonstrate that the level-of-care planning model supports mental health restructuring by identifying gaps in care, guiding hospital downsizing, and helping to enhance community mental health funding. The new funds provided to community mental health agencies in Southeastern Ontario gave us an opportunity to use the level-of-care model to evaluate whether system improvements had reduced unmet need and improved care match. To our knowledge, this is the first time that a level-of-care planning model has been used to evaluate this aspect of system performance following planned enhancements and restructuring.

\section{METHODS}

\section{Design}

We drew a representative sample from clients receiving community-based mental health care pre- and post-funding enhancements. The pre-survey was conducted during 2001 and the post-survey was conducted during 2006. Figure 1 shows the timing of the surveys in relation to the funding enhancements (Southeastern Ontario Regional Mental Health Office, 2006). No significant investments were reported prior to 1999 (Hartford, Schrecker, Wiktorowicz, Hoch, \& Sharp, 2003). There was a small increase in funds between 2000 and 2001, prior to our pre-survey. Between 2001 and 2002 funding doubled, reflecting the largest increase during the time period.

Adult clients (age 16 and over) were randomly sampled from eligible community agency lists. Community mental health agencies were eligible if they provided services to adults with serious mental disorders. These community agencies offered a range of services such as counselling, case management, assertive community treatment, and supportive housing programs. Eligible agencies also included hospitalaffiliated outpatient programs that offered team-based counselling, case-management, or assertive community treatment. Specialty sector programs serving specialized populations (forensic, acquired brain injured, psychogeriatric, and intellectually disabled clients) were excluded, as were emergency or crisis programs, fee-for-service psychiatric practices, and specialized addictions agencies. In 2001, 13 agencies were eligible and all participated. In 2006, 11 agencies were eligible and 10 participated.

Agencies provided an anonymized list of all clients who had received services during 3 target months. To identify clients who had received services in multiple agencies, a unique anonymized identification code was created from a combination of letters of the client's first and last name, gender, and date of birth. Clients with duplicate entries were assigned to the agency that offered the most intensive services, where caseworkers would be the most knowledgeable about their needs. To allow for subgroup analysis, the sample was stratified by age group: 16-25 (50\% sampling fraction), 26-65 (10\% sampling fraction), and over 65 
(100\% sampling fraction). Samples were drawn in an identical fashion and were representative of clients who received community mental health care between August and October in the year of the survey. Our 2001 sample totalled 634 clients, with 525 usable surveys returned (83\%). Our 2006 sample totalled 715 clients, with 610 usable surveys returned (85\%).

Ethics approval was obtained from Queen's University. In addition, several organizations (Quinte Hospital Group, Hotel Dieu Hospital, The Royal Ottawa Hospital Group, and Providence Care Mental Health Services) required additional ethics or administrative approvals, which we also obtained.

\section{Figure 1}

Total Year-End Community Mental Health Funding, Southeastern Ontario, 2000 to 2006

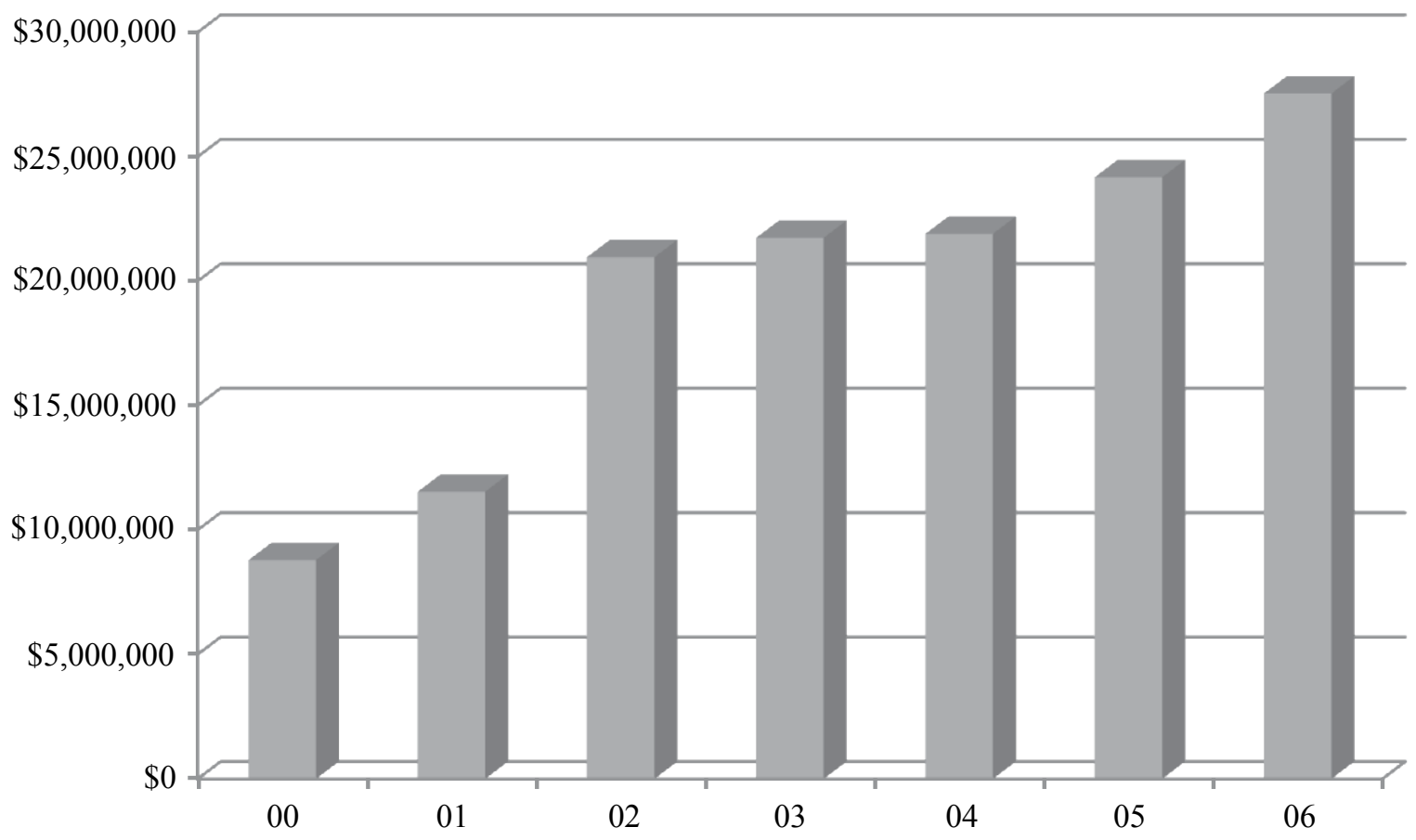

\section{Measures}

We used the level-of-care planning model developed by Durbin and colleagues to determine care match (Durbin et al., 2001). This model uses a five-level continuum of care to conceptualize clients' longer term service needs. At Level 1 (Self-Managed Care) the individual resides in the community, accesses a family physician or psychiatric services periodically as needed, and may use community services and supports intermittently at his or her own discretion. At Level 2 (Community Care), the individual resides in the community 
and needs weekly assistance with case management to identify needs and access community services and supports. Psychiatric care may be obtained from an outpatient clinic or from a private practitioner. At Level 3 (Intensive Case Management), the individual lives in the community but needs intensive (up to daily) assistance to obtain mental health treatment, rehabilitation services, and community-based services, such as intensive case management or assertive community treatment. At Level 4 (Residential Care), the individual needs 24-hour support and access to treatment and rehabilitation services in a secure community residential care setting with on-site staffing. Finally, at Level 5 (Inpatient Care), the individual needs 24-hour care provided by a multidisciplinary team of highly trained experts in a secure setting where there is capacity to do comprehensive assessment and treatment.

The planning model uses the Colorado Client Assessment Record (1997 version) to arrive at a recommended level of care. The Colorado Client Assessment Record includes 22 dimensions pertaining to symptoms, social functioning, behaviours, strengths and resources, and general health. Ratings are made by the client's primary care worker or other staff member who knows the person well. Each dimension is rated on a 9-point scale reflecting the degree of functional impairment that is of current clinical concern. No patient interview is required. A standard algorithm uses ratings from six domains (following a decision-tree format) to determine need for care. Clients are first separated into three groups based on whether their score on the security and management dimension is low (1-3), moderate (4-6), or high (7-9). Next, clients are grouped according to their overall problem severity. Those with low security and management issues and low overall problem severity are further subdivided by their score on the strengths and resources scale to identify needs for Level 1 through Level 3 care. Clients with moderate security and management issues and moderate overall problem severity scores are further subdivided by their need for assistance with self-care, and by their strengths and resources scores, to identify needs for Level 3 or Level 4 care. Finally, clients with high security and management issues and high overall problem severity scores are subdivided by their risk for violence or suicide to yield Level 4 and Level 5 care needs. A complete description of this placement algorithm is available in Durbin et al. (2001). In our application of the algorithm, we found a total of 73 clients who were placed in Level 1 care (Self-Managed Care) but who, in the opinion of their primary therapist, needed regular (at least one to three times a month) medication management. We adapted the algorithm to reclassify these individuals to Level 2 (Community Care) to reflect their higher level of need.

The second component of the planning model uses the Supports and Services Inventory to identify the level of care each client is currently receiving across 19 items grouped into treatment and rehabilitation domains. Six items refer to treatment and crisis services (such as medication management, assessment/diagnosis, substance abuse programming, or crisis intervention), and 13 items refer to rehabilitation services and other supports (such as activities of daily living, educational services, housing support, or family supports). Each item is scored on an intensity scale describing the client's current service use ranging from zero to 8 or more times a month. Clinicians are also asked to judge the extent to which clients' current service use was more than needed, less than needed, or appropriate. Comparison of these two variables yielded a measure of unmet need for each service rated.

A second algorithm is then used to hierarchically assign clients to one of the five levels of care based on the frequency and intensity of services received. Level 5 clients were inpatients at the time of the survey. Level 4 clients were in residential care. This meant that the facility was locked or lockable and was staffed 
during the day or on a 24-hour basis. The original algorithm classified all clients in nursing homes and longterm care facilities as Level 4, even though a number were able to manage their own care or obtain services from community agencies. As a consequence, they would have appeared to be overserviced when matching was completed. After consultation with local specialists in geriatric psychiatry, we decided to relax this condition. Fifty clients were identified as living in a nursing home or long-term care facility $(2001=25$; $2006=25$; only one individual was a duplicate). In 2001, 5 met the criteria for Level 1 (Self-Managed Care) and 20 met the criteria for Level 2 (Community Care). In 2006, 20 met the criteria for Level 2 (Community Care), 3 met the criteria for Level 3 (Intensive Community Care), and 2 were inpatients at the time of the survey. Level 3 clients were receiving intensive (up to daily) case management services. Level 2 clients were using community treatment and rehabilitation services (such as medication management, assessment and diagnosis, psychotherapy or counselling, self-care services, vocational services, educational services, or housing supports) at least 4-7 times per month. Finally, Level 1 clients used this same range of community treatment and rehabilitation services less frequently, or not at all.

Care match was determined by comparing the recommended level of care assigned based on the data from the Colorado Client Assessment Record (Algorithm 1) to the received level of care assigned based on the data from the Supports and Services Inventory (Algorithm 2). We recoded this information into three categories for analysis: underservicing, defined as a recommended level of care that was higher than the actual level of care; matched care, defined as a recommended level of care that was equivalent to the actual level of care; and overservicing, defined as a recommended level of care that was lower than the actual level of care received. Raters were blind to the assignment and matching rules used in this analysis.

\section{Data Collection and Management}

A training manual provided standardized operational descriptions and 5 anchor points for each scale. We used a train-the-trainer approach with vignette ratings to teach key workers from each program the logic and use of the study instruments. Raters were provided copies of the study instruments and the instruction manual. The principal investigator was present at all of the rating sessions across both waves of data collection. We used a group discussion format to present the logic of the study and discuss the requirements for each scale. Next, raters independently rated the first of several case vignettes. Ratings were then presented and discussed within the group using a round-robin format. The logic of each rating was discussed and ratings that deviated from the trainers' were reviewed in detail. Each successive vignette was rated and discussed in this manner. By the third vignette, raters agreed on most items, with occasional small deviations (1 point) from the group norm. Formal interrater reliability statistics were not collected.

The initial pool of raters then functioned as the site coordinators and "trainers" within their respective programs. They oriented program staff to the study, instructed them in the use of the tool, and answered questions about the meaning of benchmarks. Completed surveys were forwarded to a study coordinator for further review. Missing or ambiguous items and logical inconsistencies were flagged and returned to raters for correction or clarification. In the 2001 survey, 121 raters each completed an average of 4.3 surveys. In the 2006 survey, 177 raters completed an average of 3.4 surveys. In both surveys, $65 \%$ of raters had last seen their client within the month prior to the survey. Over $80 \%$ of raters in the post-survey considered they knew the client "well" or "very well." Comparable data were not collected for the pre-survey. 


\section{Analysis}

Percentages were age-weighted to account for the stratified study design. Tables do not show the raw frequency counts as these will not correspond to the weighted percentages. Chi-square statistics were appropriately weighted using the svy feature in STATA (Version 10) for unclustered data (STATA, 2007). Various mixed effects and clustered regression models (not shown) were examined to assess the impact of potential clustering of results by agency, by rater, and both. Though cluster effects were identified, the significance of our primary comparisons remained unchanged. Therefore, for ease of presentation, chi-square statistics are presented. Because we made adjustments to the algorithms, we show our main results for both the original and the adapted algorithm.

\section{RESULTS}

Using the combined agency logs reflecting all unique clients served by community mental health programs in our study, we determined that 3,163 clients were served in 2001 compared to 3,537 in 2006, reflecting an increase of $12 \%$ (some 350 clients). Thirty-three clients (2.9\%) appeared in both samples. Over the same time, the population of the Southeastern Ontario health region had grown by less than 1 percent (Health System Intelligence Project, 2009).

Table 1 presents selected sociodemographic and clinical characteristics for the clients included in each sample and shows statistically significant differences in several variables. In 2006, more clients were male, younger, unmarried, with schizophrenia, or using psychotropic medications. While this suggests a more seriously ill population, the average problem severity rating provided by clinical care workers did not change over this time. Average ratings placed clients in the slight to moderate range in both surveys. This rating indicates that problems may be intermittent or persist at a low or moderate level, with the possibility of becoming severe on occasion. There were no differences in employment status or in the proportion of clients diagnosed with mood, anxiety, substance-related, personality, eating, or organic disorders. The majority of clients were not working and over half of the clients were diagnosed with a mood disorder.

Table 2 shows the percentage of clients who used any treatment and rehabilitation services as well as the percentage who were deemed by the primary worker to have unmet needs in these areas. With respect to treatment services, the proportion of clients using crisis intervention and physical health care declined in the second survey by $8 \%$ and $6 \%$ respectively. Otherwise, access to all other treatment services increased, though differences were less than 5\%. By 2006, the largest area of unmet need, also the area with the least use, was substance abuse programming. The largest increases in service use occurred in rehabilitation supports and services, particularly in programs supporting meaningful activities, vocational rehabilitation, and income/financial assistance. However, in 2006, rehabilitation supports and services, particularly vocational activities, education, and peer support services, were still deemed to be the areas of highest unmet need.

Table 3 describes the extent to which levels of care matched clients' needs. There was a $6 \%$ increase in the percentage of clients who were matched; however, this was not statistically significant. In 2006, the bulk of clients - almost half - remained underserviced (reflecting an 8\% decrease from 2001), and one in 
Table 1

Selected Client Characteristics

\begin{tabular}{|c|c|c|}
\hline Characteristic & $\begin{array}{l}2001 \text { Survey } \\
\%(\mathrm{CI})\end{array}$ & $\begin{array}{c}2006 \text { Survey } \\
\%(\mathrm{CI})\end{array}$ \\
\hline \multicolumn{3}{|l|}{ Gender: } \\
\hline - Male & 36.8 & 44.2 \\
\hline - Female & 63.2 & 55.8 \\
\hline \multicolumn{3}{|l|}{$\cdot \chi_{(d f=1)}^{2}=6.45, p=.05$} \\
\hline \multicolumn{3}{|l|}{ Age group: } \\
\hline$\cdot 16-24$ & 8.7 & 11.7 \\
\hline - 25-64 & 85.0 & 81.5 \\
\hline$\cdot 65+$ & 6.3 & 6.7 \\
\hline \multicolumn{3}{|l|}{$\cdot \chi_{(d f=2)}^{2}=2.9, p<.01$} \\
\hline \multicolumn{3}{|l|}{ Marital status: } \\
\hline - Married/common law & 31.6 & 26.6 \\
\hline - Single & 42.9 & 47.6 \\
\hline - Separated & 9.5 & 4.9 \\
\hline - Divorced & 13.4 & 18.0 \\
\hline - Widowed & 2.6 & 3.0 \\
\hline$\cdot \chi_{(d f=4)}^{2}=16.4, p=.04$ & & \\
\hline \multicolumn{3}{|l|}{ Employment status: } \\
\hline - Working full-time & 13.8 & 9.7 \\
\hline - Working part-time (regular) & 8.6 & 8.6 \\
\hline - Working part-time (casual) & 5.0 & 6.5 \\
\hline - Not working & 72.5 & 75.3 \\
\hline$\cdot \chi_{(d f=3)}^{2}=5.4, p=.38$ & & \\
\hline \multicolumn{3}{|l|}{ Diagnosis: } \\
\hline - Mood disorder & $55.8(51.6,60.1)$ & $57.2(53.2,61.1)$ \\
\hline - Anxiety disorder & $24.1(20.5,27.8)$ & $23.0(19.6,26.3)$ \\
\hline - Schizophrenia & $24.6(20.9,28.3)$ & $32.6(28.9,36.3)$ \\
\hline - Substance-related disorder & $13.7(10.8,16.7)$ & $17.4(14.4,20.5)$ \\
\hline - Personality disorder & $13.7(10.8,16.7)$ & $18.9(15.7,22.0)$ \\
\hline - Eating disorder & $4.7(2.9,6.5)$ & $6.0(4.2,8.0)$ \\
\hline - Organic disorder & $2.8(1.4,4.2)$ & $1.6(0.06,2.6)$ \\
\hline Psychotropic medication use & $72.0(68.1,75.8)$ & $79.9(76.7,83.1)$ \\
\hline Average problem severity & $4.3(4.4,4.7)$ & $4.4(4.2,4.5)$ \\
\hline
\end{tabular}

Note. All estimates are weighted to account for stratified sampling design. Diagnosis is a multiple response item so percentages will not add to 100 . Numbers in parentheses reflect $95 \%$ confidence intervals. Average problem severity is measured on a scale of 1 (none) to 9 (severe). Raw numbers are not shown as they will not directly correspond to the weighted percentages. 
Table 2

Areas of Unmet Need

\begin{tabular}{|c|c|c|c|c|}
\hline \multirow{2}{*}{$\begin{array}{l}\text { Area of service need } \\
\text { (as judged by clinical caseworkers) }\end{array}$} & \multicolumn{2}{|c|}{2001 Survey } & \multicolumn{2}{|c|}{2006 Survey } \\
\hline & $\begin{array}{c}\text { Services used } \\
(\%)\end{array}$ & $\begin{array}{l}\text { Unmet need } \\
(\%)\end{array}$ & $\begin{array}{c}\text { Services used } \\
(\%)\end{array}$ & $\begin{array}{c}\text { Unmet need } \\
(\%)\end{array}$ \\
\hline \multicolumn{5}{|l|}{ Treatment and crisis services: } \\
\hline - Medication management & 56.7 & 18.4 & 61.0 & 7.9 \\
\hline - Assessment/diagnosis & 53.9 & 7.5 & 61.1 & 6.9 \\
\hline - Psychotherapy/counselling & 71.1 & 8.1 & 73.9 & 12.9 \\
\hline - Substance abuse programming & 9.6 & 13.1 & 11.5 & 15.0 \\
\hline - Crisis intervention & 44.9 & 9.5 & 37.0 & 10.0 \\
\hline - Physical health care & 73.2 & 5.7 & 67.6 & 7.9 \\
\hline \multicolumn{5}{|l|}{ Rehabilitation and other supports: } \\
\hline - Self-care (hygiene, dressing) & 17.3 & 6.2 & 19.0 & 6.2 \\
\hline - Other ADL (shopping, housework) & 23.2 & 7.6 & 29.0 & 8.5 \\
\hline - Vocational & 10.5 & 23.3 & 21.7 & 20.3 \\
\hline - Meaningful activity (hobbies) & 32.1 & 23.6 & 52.2 & 15.4 \\
\hline - Educational & 12.3 & 18.1 & 13.1 & 17.8 \\
\hline - Social/recreational & 46.3 & 15.0 & 54.8 & 15.5 \\
\hline - Housing support & 22.5 & 8.4 & 23.3 & 7.2 \\
\hline - Income/financial assistance & 37.0 & 10.7 & 48.1 & 7.5 \\
\hline - Rights protection \& advocacy & 23.3 & 7.6 & 20.7 & 9.6 \\
\hline - Support to family caregivers & 24.8 & 11.0 & 28.7 & 8.3 \\
\hline - Correction/probation/court services & 41.8 & 1.1 & 54.5 & 0.4 \\
\hline - Developmental disability programming & 38.9 & 1.6 & 21.6 & 1.5 \\
\hline - Peer support & -- & -- & 35.6 & 17.8 \\
\hline
\end{tabular}

Note. The need for peer support services was not collected in 2001. Results are appropriately age weighted to take account of the stratified sampling design. Raw numbers are not shown as they will not directly correspond to the weighted percentages. $\mathrm{ADL}=$ activities of daily living. 
five clients were overserviced (reflecting a $2 \%$ increase from 2001). Similar results were obtained using the original and adapted algorithms. Table 3 also shows that the percentage of clients who received a level of care that matched their needs differed depending on their recommended level of care. Whereas overservicing occurred most frequently for Level 1 (Self-Managed Care) clients, underservicing was the major problem at Level 3 (Intensive Community Care).

Table 3

Level of Care (LOC) Received Compared to the Level of Care Recommended (Rec)

\begin{tabular}{|c|c|c|c|}
\hline Recommended level & $\begin{array}{c}\mathrm{LOC}<\mathrm{Rec} \\
(\%)\end{array}$ & $\begin{array}{c}\mathrm{LOC}=\mathrm{Rec} \\
(\%)\end{array}$ & $\begin{array}{c}\mathrm{LOC}>\mathrm{Rec} \\
(\%)\end{array}$ \\
\hline \multicolumn{4}{|l|}{ All levels (adapted algorithm) } \\
\hline • 2001 & 50.6 & 32.1 & 17.4 \\
\hline • 2006 & 42.5 & 38.1 & 19.4 \\
\hline \multicolumn{4}{|l|}{$\cdot \chi_{(d f=2)}^{2}=6.88, p=.13$} \\
\hline \multicolumn{4}{|l|}{ All levels (original algorithm) } \\
\hline$\cdot 2001$ & 50.5 & 30.8 & 17.7 \\
\hline • 2006 & 41.3 & 34.8 & 23.9 \\
\hline \multicolumn{4}{|l|}{$\cdot \chi_{(d f=2)}^{2}=9.2, p=.06$} \\
\hline \multicolumn{4}{|l|}{ Level 1} \\
\hline • 2001 & 0 & 67.5 & 32.5 \\
\hline • 2006 & 0 & 61.9 & 38.1 \\
\hline \multicolumn{4}{|l|}{$\cdot \chi_{(d f=1)}^{2}=3.6, p=.56$} \\
\hline \multicolumn{4}{|l|}{ Level 2} \\
\hline • 2001 & 53.7 & 30.9 & 15.4 \\
\hline • 2006 & 41.9 & 42.0 & 16.2 \\
\hline \multicolumn{4}{|l|}{$\cdot \chi_{(d f=2)}^{2}=16.69, p=.07$} \\
\hline \multicolumn{4}{|l|}{ Level 3} \\
\hline • 2001 & 77.5 & 10.3 & 12.3 \\
\hline • 2006 & 70.5 & 13.1 & 10.5 \\
\hline - $\chi_{(d f=2)}^{2}=6.88, p=.626$ & & & \\
\hline
\end{tabular}

Note. $2001=525$ clients; $2006=610$ clients. Level 4 and 5 clients are excluded from this analysis owing to their small numbers in the sample and potentially misleading results. Results are appropriately age weighted to take account of the stratified sampling design. Raw numbers are not shown as they will not directly correspond to the weighted percentages. 


\section{DISCUSSION}

This study assessed improvements in access to care for, and appropriateness of care delivered to, community mental health clients in Southeastern Ontario following funding enhancements. Almost \$19 million was invested in the Southeastern Ontario community mental health system between the pre- and post-surveys, reflecting a doubling of resources. Community mental health programs served an estimated $12 \%$ more clients (approximately 350 unique individuals) in 2006 than in 2001 . At the same time, the health region's population grew by less than 1 percent, suggesting that programs were achieving better coverage in addressing the community's unmet need. There were small and non-statistically significant increases in the proportion of clients who received a level of care that matched their needs. In 2006, underservicing remained a problem for almost half of the clients. Underservicing was particularly problematic for clients who should have received Level 3 care (Intensive Community Care), where 71\% received a level of care that was less than optimal. Overservicing occurred less frequently (in about $20 \%$ of clients), but most often for individuals who were considered able to self-manage their care (38\%). The most frequent areas of unmet need identified by caseworkers in both surveys were for social and vocational services.

Although effective mental health treatment often involves complex processes of care spanning multiple care providers, agencies, and even systems of care, only rarely have evaluations considered the effects of system-level changes on the quality of care provided or client outcomes (Barnes, Stein, \& Rosenberg, 1999). Therefore, an important strength of this study is that it examined needs for care using a system-level evaluation of community mental health services. Secondly, there are relatively few validated methods for determining the level of care needed by clients of mental health services (Hansen et al., 2007). The level-of-care planning model used in this evaluation has been shown to have good concurrent validity and to use well-validated tools to gather symptom and functional data (Durbin et al., 2001). Though some studies have found reasonable correlations among the perspectives of clients, parents, and clinical care providers (Foldemo, Ek, \& Bogren, 2004; Holley, Hodges, \& Jeffers, 1998), this approach is based on clinical care workers' reports. As clients may disagree with their care providers concerning their needs for care, including not perceiving any need even when seriously impaired (Kessler et al., 2001), results from this investigation should not be used to draw inferences about client perspectives. Rather, results should be considered to reflect the system's capacity (or predisposition) to provide appropriate services to those who seek help.

We report a small and non-significant increase in care match. Our post-survey occurred in the same year that the final funding instalments were received and 5 years following our first evaluation. It may be that insufficient time had passed to allow community programs to fully redevelop or train a new staff complement (some programs doubled in size), stabilize internal processes, or forge new and expanded systems of care. However, the largest funding increase occurred in 2002, so agencies should have had sufficient time to enhance their services prior to our post-survey. Despite this, we do not know how the new funding impacted specific agencies. Therefore the extent to which service provision was disrupted and improvements delayed remains speculative. We are unaware of any other changes to system functioning that may have occurred during the same time period to account for our findings.

A second explanation may be that the new resources provided by the Ministry were not targeted to the areas of greatest need. Thirteen of the 19 services identified in the Supports and Services Inventory to 
determine current level of care referred to social and vocational services. Social and vocational services were not the target of the funding enhancements, and although use of these services increased over time, they remained the areas of greatest unmet need. A third explanation may be that new funding was used to relieve waiting list pressures and expand existing service coverage (doing more of the same), rather than to redistribute resources to better meet the needs of existing clients (doing things differently). This would explain the $12 \%$ increase in the number of clients served and the lack of improvement in care match. The tools needed to readjust service provision, such as standardized intake assessments designed to match services to needs, or centralized intake programs, were not widely implemented at the time of the post-survey.

Results from system-level evaluations such as this one have often been meagre. For example, a cluster randomized trial of a novel intervention designed to improve the match of community mental health services in four European sites (Wiersma et al., 2008) showed that "unmet needs" decreased over time in both treatment and control groups while "met needs" remained stable with no improvements. Consequently, there was no indication that the novel intervention had been effective. In the Fort Bragg study, Bickman (1996) examined the effects of a comprehensive and coordinated system of child mental health services. Though the new system of care was judged to have been implemented appropriately (with fidelity to the original specifications), there were no differences in key child or family outcome measures and the new, coordinated system of care was more expensive. Clinicians did not control costs by placing clients in the most appropriate level of care for the most appropriate length of time. These results, though disappointing, highlight the importance of assessing system change against performance indicators such the ones used in this research.

To conclude, this evaluation has shown that the infusion of new resources to community mental health agencies providing a range of assertive community supports was followed by improved coverage (with $12 \%$ more clients accessing services), but no substantive improvement in service match. These results suggest that a more targeted and systematic approach to care planning is now necessary in order to shift systemwide resources to client groups who are in the greatest need.

\section{RÉSUMÉ}

Dans cet article, nous mesurons l'accès aux services et l'adéquation entre le niveau de soins et les besoins, dans le Sud-Est de l'Ontario, à la suite de l'accroissement du financement en santé mentale communautaire ; pour ce faire, nous avons eu recours à des échantillons de bénéficiaires et nous avons comparé les données ainsi obtenues avant et après le nouveau financement. L'accès aux services a augmenté d'environ $12 \%$ (350 bénéficiaires de soins) entre 2001 et 2006 ; toutefois, les soins étaient d'un niveau adéquat pour seulement environ un tiers des bénéficiaires. L'adéquation entre les soins et les besoins a légèrement augmenté après l'accroissement du financement, mais ces changements ne sont pas statistiquement significatifs. Presque la moitié des bénéficiaires n'avaient pas accès à un niveau de soins suffisant, et $20 \%$ avaient accès à un niveau de soins trop élevé pour leur état. Cela indique qu'une organisation des soins mieux ciblée et plus systématique est nécessaire pour assurer que les ressources disponibles dans l'ensemble du système soient mieux utilisées, c'est-à-dire pour que les groupes de bénéficiaires dont les besoins sont les plus grands puissent en profiter. 


\section{REFERENCES}

Alonso, J., Codony, M., Kovess, V., Angermeyer, M.C., Katz, S.J., Haro, J.M., . . Brugha, T.S. (2007). Population level of unmet need for mental healthcare in Europe. British Journal of Psychiatry, 190, 299-306.

Barnes, J., Stein, A., \& Rosenberg, W. (1999). Evidence-based medicine and evaluation of mental health services: Methodological issues and future directions. Archives of Diseases in Childhood, 80, 280-285.

Bickman, L. (1996). A continuum of care. More is not always better. American Psychologist, 51, 689-701.

Durbin, J., Baranek, P., Koegl, C., Macfarlane, D., Aitchison-Drake, C., \& Goering, P. (2002). Toronto-Peel Comprehensive Assessment Project final report. Toronto, ON: Health Systems Research and Consulting Unit, Centre for Addiction and Mental Health.

Durbin, J., Cochrane, J., Goering, P., \& Macfarlane, D. (2001). Needs-based planning: Evaluation of a level-of-care planning model. Journal of Behavioral Health Services and Research, 28(1), 67-80.

Durbin, J., Koegl, C., Macfarlane, D., Sheldon, T., Aitchison-Drake, C., \& Goering, P. (2002). Champlain District Community Assessment Project. Toronto, ON: Health Systems Research and Consulting Unit, Centre for Addiction and Mental Health.

Foldemo, A., Ek, A.C., \& Bogren, L. (2004). Needs in outpatients with schizophrenia, assessed by the patients themselves and their parents and staff. Social Psychiatry and Psychiatric Epidemiology, 39, 381-385.

Hansen, L., Houde, D., McDowell, M., \& Dixon, L. (2007). A population-based needs assessment for mental health services. Administration and Policy in Mental Health and Mental Health Services Research, 34, 233-242.

Hartford, K., Schrecker, T., Wiktorowicz, M., Hoch, J.S., \& Sharp, C. (2003). Four decades of mental health policy in Ontario, Canada. Administration and Policy in Mental Health, 31(1), 65-73.

Health System Intelligence Project. (2009). Population health profile: South East LHIN. Retrieved from www.health. gov.on.ca

Holley, H.L., Hodges, P., \& Jeffers, B. (1998). Moving psychiatric patients from hospital to community: Views of patients, providers, and families. Psychiatric Services, 49(4), 513-517.

Kessler, R.C., Berglund, P.A., Bruce, M.L., Koch, R.R., Laska, E.M., Leaf, P.J., . . Wang, P.S. (2001). The prevalence and correlates of untreated serious mental illness. Health Services Research, 36(6), 987-1007.

McGee, M.D., \& Mee-Lee, D. (1997). Rethinking patient placement: The human service matrix model for matching services to needs. Journal of Substance Abuse Treatment, 14(2), 141-148.

Ruggeri, M., Leese, M., Slade, M., Bonizzato, P., Fontecedro, L., \& Tansella, M. (2004). Demographic, clinical, social and service variables associated with higher needs for care in community psychiatric service patients. The South Verona outcome project 8. Social Psychiatry and Psychiatric Epidemiology, 39, 60-68.

Sareen, J., Cox, J.J., Afifi, T.O., Clara, I., \& Yu, B.N. (2005). Perceived need for mental health treatment in a nationally representative Canadian sample. Canadian Journal of Psychiatry, 50, 643-651.

Southeastern Ontario Regional Mental Health Office. (2006). Southeastern Ontario community mental health system. Unpublished slide presentation.

STATA 10. (2007). Survey data reference manual. STATA Press.

Stuart, H.L. (2002). Matching community mental health services to needs. Results of the Southeastern Ontario Community Comprehensive Assessment Project. Kingston, ON: The Southeastern Ontario Mental Health Implementation Task Force.

Systems Enhancement Evaluation Initiative. (2009). Seeing a difference: Demonstrating the impact of new investments in our community mental health system. Toronto, ON: Health Systems Research and Consulting Unit, Centre for Addiction and Mental Health.

Uehara, E.S., Srebnik, D., \& Smukler, M. (2003). Statistical and consensus-based strategies for grouping consumers in mental health level-of-care schemes. Administration and Policy in Mental Health, 30(4), 287-306.

Vasiliadis, H.M., Lesage, A., Adair, C., \& Boyer, R. (2005). Service use for mental health reasons: Cross-provincial differences in rates, determinants, and equity of access. Canadian Journal of Psychiatry, 50, 614-619.

Wiersma, D., van den Brink, R., Wolters, K., McCabe, R., Bullenkamp, J., Hansson, L., . . Priebe, S. (2008). Individual unmet needs for care: Are they sensitive as outcome criterion for the effectiveness of mental health services interventions? Social Psychiatry and Psychiatric Epidemiology, 44(4), 317-324. 
